\title{
Linkage mapping and phenotypic analysis of autosomal dominant Pallister-Hall syndrome
}

\author{
National Human \\ Genome Research \\ Institute, National \\ Institutes of Health, 49 \\ Convent Drive, Room \\ 4A80, Bethesda, MD \\ 20892, USA \\ $S$ Kang \\ E Green \\ A Schäffer \\ L G Biesecker
}

Clinical Center,

National Institutes of

Health, Bethesda, MD, USA

N Patronas

National Institute for Deafness and Communicative Disorders, National Institutes of Health Bethesda, MD, USA F Ondrey

Department of Neurology, Beth Israel Hospital, North, New York, NY, USA

$\mathrm{J}$ Allen

Medical Genetics Birth Defects Center, Ahmanson

Department of

Pediatrics,

Cedars-Sinai Medical

Center and UCLA

School of Medicine,

Los Angeles, CA, USA

J M Graham Jr

Department of

Pediatrics, University

of Arizona, Phoenix,

AZ, USA

T Grebe

\section{Department of}

Pediatrics, University

of New Mexico,

Albuquerque, NM,

USA

C Clericuzio

Departments of

Medicine and

Psychiatry, Johns

Hopkins University,

Baltimore, MD, USA

M Abbott

Correspondence to:

Dr Biesecker.

Received 28 February 1997 Revised version accepted for publication 20 March 1997

Seongman Kang, Jeffrey Allen, John M Graham Jr, Theresa Grebe, Carol Clericuzio, Nicholas Patronas, Frank Ondrey, Eric Green, Alejandro Schäffer, Margaret Abbott, Leslie G Biesecker

Abstract

Pallister-Hall syndrome is a human developmental disorder that is inherited in an autosomal dominant pattern. The phenotypic features of the syndrome include hypothalamic hamartoma, polydactyly, imperforate anus, laryngeal clefting, and other anomalies. Here we describe the clinical characterisation of a family with 22 affected members and the genetic mapping of the corresponding locus. Clinical, radiographic, and endoscopic evaluations showed that this disorder is a fully penetrant trait with variable expressivity and low morbidity. By analysing 60 subjects in two families using anonymous STRP markers, we have established linkage to 7 p13 by two point analysis with D7S691 resulting in a lod score of 7.0 at $\theta=0$, near the GLI3 locus. Deletions and translocations in GLI3 are associated with the Greig cephalopolysyndactyly syndrome. Although Greig cephalopolysyndactyly syndrome has some phenotypic overlap with Pallister-Hall syndrome, these two disorders are clinically distinct. The colocalisation of loci for these distinct phenotypes led us to analyse GLI3 for mutations in patients with Pallister-Hall syndrome. We have previously shown GLI3 mutations in two other small, moderately affected families with PallisterHall syndrome. The linkage data reported here suggest that these larger, mildly affected families may also have mutations in GLI3.

( $\mathcal{}$ Med Genet 1997;34:441-446)

Keywords: linkage mapping; polydactyly; hypothalamic hamartoma; epiglottis

Pallister-Hall syndrome (PHS) was originally described in 1980 in a group of six newborns who died with a unique and severe cluster of anomalies. ${ }^{12}$ The characteristic malformations in these children included hypothalamic hamartoma, central polydactyly, endocrine dysfunction, clefting of the larynx and epiglottis, and other malformations. Subsequently, less severe familial cases have been described and reviewed. ${ }^{34}$ These reports have established that central polydactyly and hypothalamic hamartoma comprise a distinct malformation syndrome. Whether this familial syndrome is aetiologically distinct from the lethal sporadic cases cannot be answered by clinical analysis alone and requires genetic and molecular analyses.

The proband of family 1 was diagnosed with PHS because of her polydactyly and hypothalamic hamartoma. The family history indicated that 22 members of her family were affected by polydactyly. This family is the largest yet reported with PHS and supports the hypothesis that the disorder is an autosomal dominant trait with variable expressivity. ${ }^{5}$ Here we report the clinical features of this family and linkage data derived from family 1 and an additional family.

\section{Methods}

PEDIGREE ASCERTAINMENT AND PHENOTYPIC ANALYSIS OF FAMILY 1

The members of family 1 were examined by one of the authors (17 cases) or a referring physician (five cases). This research study was reviewed and approved by the NIH National Cancer Institute Institutional Review Board. Subjects were determined to be affected using published criteria for PHS. ${ }^{3}$ Outside clinical records and copies of imaging studies were obtained from personal physicians with the consent of the subjects. The subjects were evaluated by physical examination, magnetic resonance imaging of the CNS with a GE 1.5 Tesla scanner, flexible fibreoptic direct laryngoscopy, and limb radiographs.

\section{LINKAGE ANALYSIS}

Peripheral blood samples were obtained from 44 members of family 1 and 16 members of a previously reported family. ${ }^{6}$ Genomic DNA was purified by affinity chromatography from RBC lysed whole blood (Qiagen Corp). Markers were selected from the CEPH database or Marshfield screening set 6.0 (Research Genetics, Inc) and amplified with $\alpha^{32}$ PdCTP incorporation and scored manually. Markers were 


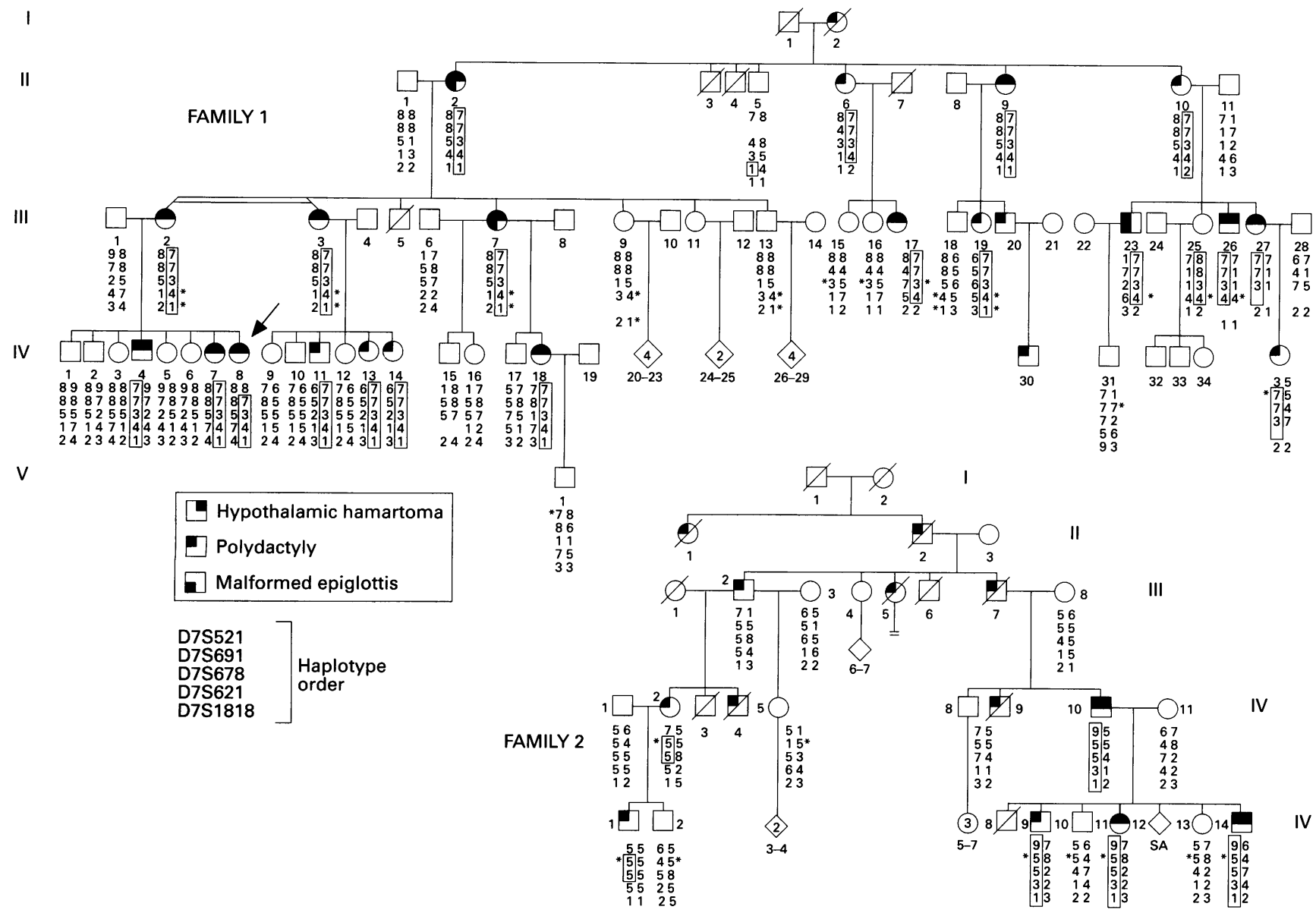

Figure 1 The pedigrees of the families (1 and 2) used in the linkage analysis. This figure also shows the haplotype analysis for markers D7S521, D7S691, D7S678, D7S621, and D7S1818. The asterisk denotes an allele in an offspring of an affected parent homozygous for that allele. Note that the haplotypes in family 2 are arbitrarily set based on the offspring of subject IV.10.

selected from the set beginning with chromosomes that had been partially analysed in previous linkage exclusion work. ${ }^{7}$ The linkage analysis calculations were done with FASTLINK (version 3.0P) ${ }^{89}$ which is a faster version of LINKAGE, ${ }^{10}$ using an autosomal dominant model with full penetrance, a mutant allele frequency of 0.0001 , and gender independent recombination frequencies. These initial assumptions of penetrance, gene frequency, and gender independence were based on our experience with this disorder and were considered working hypotheses. Because these initial assumptions yielded positive results, alternative hypotheses were not considered. The multilocus calculations were done in parallel ${ }^{11}$ using FASTLINK on top of the TreadMarks distributed shared memory system ${ }^{12}$ running on an IBM SP2 parallel computer at the Division of Computer Research and Technology of NIH. Haplotype analysis was performed manually by minimising recombinants. YAC based physical mapping was performed as previously described. ${ }^{13-17}$

\section{Results}

CLINICAL ANALYSIS OF FAMILY 1

The proband (IV.8, fig 1) is a 21 month old child who was noted to have ptosis and polydactyly at the time of birth. This finding prompted an ophthalmological and neurological evaluation including a cranial MRI examination. The cranial MRI showed

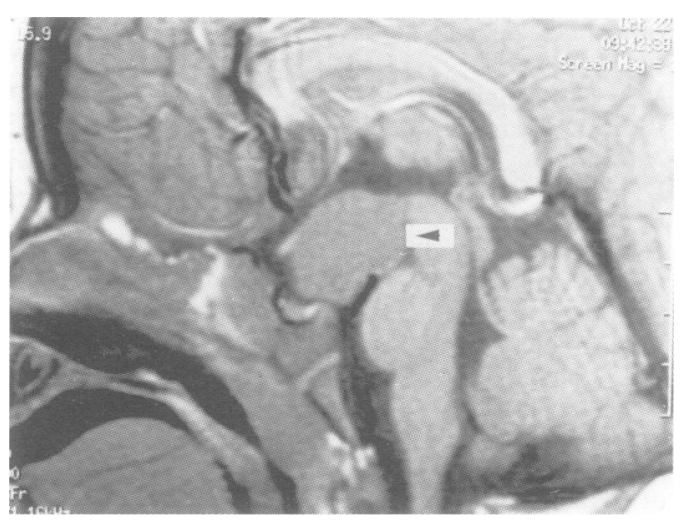

Figure 2 Sagittal cranial magnetic resonance image of subject IV.8. The arrowhead indicates the mass of the hypothalamic region, diagnosed as a hamartoma by the MRI signal characteristics.

that she had a $2 \times 2.5 \times 3 \mathrm{~cm}$ mass in the area of the hypothalamus that did not enhance with gadolinium (fig 2). The MRI finding was compatible with a hypothalamic hamartoma.

The family history showed that she had 21 relatives with polydactyly in an autosomal dominant pattern (fig 1). The pedigree includes nine obligate heterozygotes, all of whom have some manifestation of the disorder. The gender ratio of the affected members is six males to 16 females (however, note that family 2 has nine affected males and only four females). There is one instance of male to male transmission (from III.20 to IV.30). I.2 is 
Table 1 Clinical features of family 1

\begin{tabular}{lllllll}
\hline Pedigree No & Hamartoma & Left hand & Right hand & Left foot & Right foot & Epiglottis \\
\hline II.2 & $<1 \times 1 \times 1$ & PostPA & PostPA & PostPA & PostPS & Abnormal \\
II.6 & & PostPB & PostPB & PostPA & PostPA & \\
II.9 & $1 \times 1 \times 1$ & PostPA & PostPA & CentralPS & CentralPS & \\
II.10 & & $?$ & $?$ & PostP & PostP & \\
III.2 & $1.5 \times 1.5 \times 1.5$ & PostPA & PostPA & CentralPS & CentralPS & Normal \\
III.3 & $1.5 \times 2 \times 2$ & PostPA & PostPA & PostPA & PostPA & Normal \\
III.7 & $3 \times 3 \times 2.5$ & PostPS & PostPA & 23TSyn & $23 T S y n$ & Bifid \\
III.17 & Present & Poly & Poly & Poly & Poly & \\
III.19 & & $?$ & $?$ & Poly & Poly & \\
III.20 & & $?$ & $?$ & Poly & Poly & \\
III.23 & Normal & Poly & Poly & Poly & Poly & Bifid \\
III.26 & $1.5 \times 1.5 \times 1$ & PostPA & PostPA & CentralPS & PostPA & Normal \\
III.27 & $<1 \times 1 \times 1$ & PostPA & PostPS & PostPA & PostPA & \\
IV.4 & & PostPA & PostPA & CentralPS & CentralPS & \\
IV.7 & $2 \times 2 \times 2$ & PostPA & PostPA & CentralPS & CentralPS & Normal \\
IV.8 & $2 \times 3 \times 2.5$ & PostPA & PostPB & CentralPS & CentralPS & Normal \\
IV.11 & & Post & Post & Post & Post & \\
IV.13 & & PostPA & PostPB & PostPA & PostPA & Normal \\
IV.14 & & CentralPS & PostPA & PostPA & PostPA & Normal \\
IV.18 & $3 \times 2.5 \times 3$ & Post & Post & Post & Post & \\
IV.30 & & PostP & PostP & PostP & PostP & \\
IV.35 & & PostPA & PostPS & PostPA & PostPA & \\
\hline
\end{tabular}

PostPA=postaxial polydactyly type $A$, PostPB=postaxial polydactyly type $B$, PostPS=postaxia polysyndactyly, Poly=polydactyly, type unspecified, CentralPS=central polysyndactyly, 23TSyn=partial cutaneous syndactyly of toes 2 and 3, ?=limb malformation not known. A hamartoma is present in III. 17 but the size is not known.

reported to have had polydactyly but no supporting documents are available.

The affected members of family 1 are in good general health and have normal intellectual development. One sib of the proband has learning disabilities but is not developmentally delayed. All members of family 1 have normal craniofacial features including head circumference and interpupillary distances. Four members of family 1 have had psychiatric diagnoses including depression and schizophrenia. However, one of those four is unaffected by PHS. III. 17 was diagnosed with gelastic epilepsy at 7 years of age (gelastic epilepsy is a rare partial complex seizure disorder that is characterised by uncontrolled laughing in the ictal phase). She is now treated with gabapentin and has been free of seizures for several years. IV. 18 was admitted to hospital for headache and depression at 15 years of age. An MRI scan showed a mass in the hypothalamus and she underwent a biopsy of that lesion. The histology of that tissue was reported as a hamartoma.

Twelve of the 22 affected persons in family 1 have undergone cranial MRI imaging either as a part of this study or for medical indications. Of those 12 persons, all but two had obvious masses of the tuber cinereum that were compatible with a hypothalamic hamartoma. These masses ranged from less than $1 \times 1 \times 1$ to $2.5 \times 3.0 \times 3.0 \mathrm{~cm}$ in dimension (table 1 ). In all cases, the pituitary gland was present and normally formed. The masses were isointense to gray matter on all pulse sequences and did not enhance with gadolinium. Of the two persons who did not have an obvious hypothalamic mass, one (II.2) has a slight protrusion of the posterior hypothalamus that could be a normal variant. The second person (III.23) has no evidence of a hypothalamic mass. No scan showed evidence of increased intracranial pressure or mass effect. There was no clinical evidence of optic neuropathy, visual field cuts, or endocrine dysfunction. There is no clinical evidence of progression or expansion of the hamartomas,
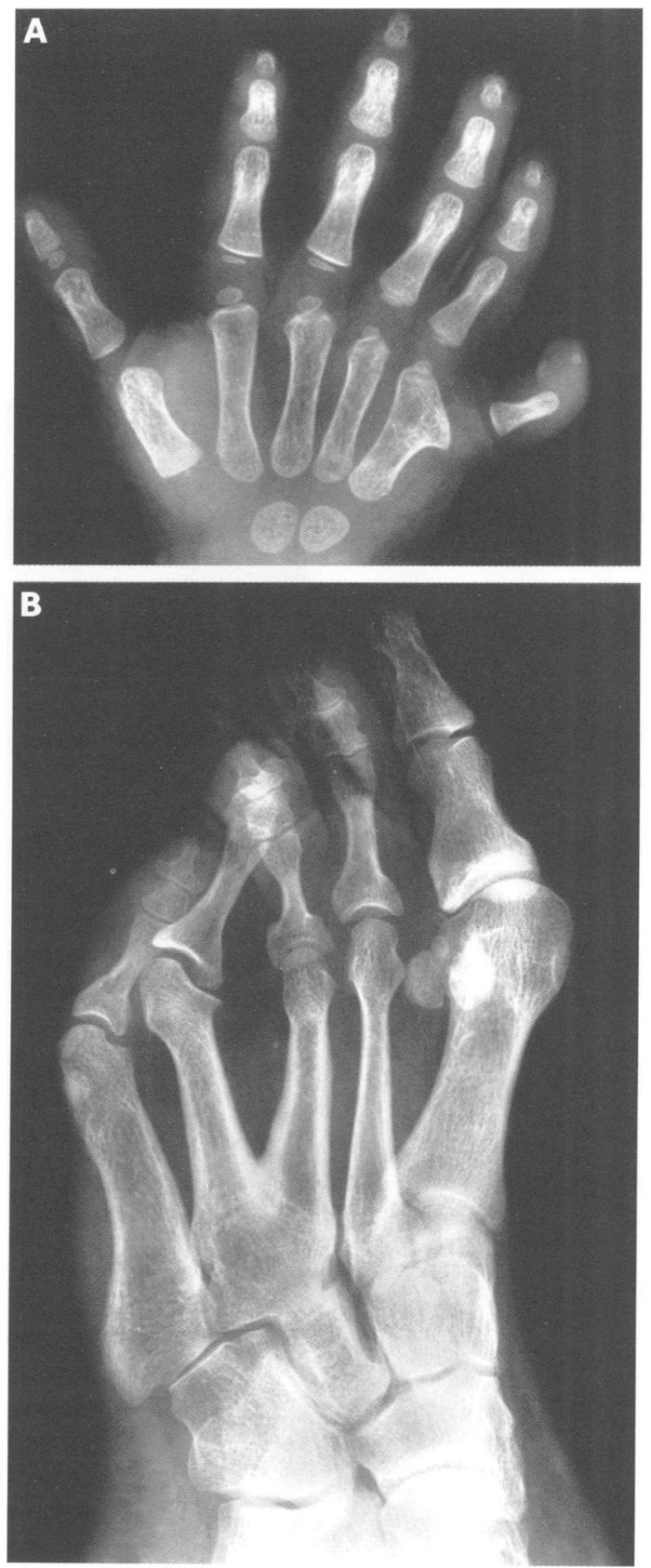

Figure 3 Radiographs of limb malformations seen in family 1. (A) Postaxial polydactyly type $A$ with a $Y$ shaped fifth metacarpal bone and small distal phalanges in IV.8. (B) Central polysyndactyly of the foot in II.9. The valgus deformity of the fourth and fifth digits was present at birth with an additional digit that articulated with the head of the fifth metatarsal. The radiograph shows forked metatarsal (digits 3 and 4). This radiograph is

postoperative and does not show that the patient had another digit articulating with the 5th metatarsal, associated with the hallucal deviation of the 4th and 5th rays.

consistent with previous experience with this disorder. ${ }^{34}$

Polydactyly was present in all 22 affected persons, which is expected since it was used as the primary feature for patient recruitment into the study (table 1). The polydactyly was markedly variable in family 1 and included postaxial polydactyly types A (fully formed supernumerary digit) (fig $3 \mathrm{~A}$ ) and $\mathrm{B}$ (digitus minimus) as well as central polysyndactyly (fig 3B). Most people had four limb polydactyly although one person had polydactyly limited to the hands (III.17). Most affected persons in family 1 had 
Table 2 Two point linkage scores

\begin{tabular}{lllllllll}
\hline \multirow{9}{*}{ Marker } & \multicolumn{9}{l}{ Recombination fraction } \\
\cline { 2 - 9 } & 0 & 0.01 & 0.025 & 0.05 & 0.1 & 0.2 & 0.3 & 0.4 \\
\hline D7S521 & $-\infty$ & 6.18 & 6.74 & $\mathbf{6 . 9 3}$ & 6.71 & 5.56 & 3.96 & 1.99 \\
D7S691 & $\mathbf{7 . 0 0}$ & 6.88 & 6.70 & 6.39 & 5.75 & 4.39 & 2.90 & 1.31 \\
D7S678 & $-\infty$ & 8.26 & $\mathbf{8 . 4 0}$ & 8.27 & 7.68 & 6.06 & 4.14 & 2.05 \\
D7S621 & 5.23 & 7.39 & $\mathbf{7 . 5 6}$ & 7.48 & 6.98 & 5.57 & 3.87 & 2.00 \\
D7S1818 & $-\infty$ & 5.01 & 5.59 & $\mathbf{5 . 8 3}$ & $\mathbf{5 . 7 3}$ & 4.80 & 3.46 & 1.82 \\
D7S665 & $-\infty$ & 0.62 & 1.94 & 2.84 & $\mathbf{3 . 4 5}$ & 3.34 & 2.56 & 1.42 \\
D7S1830 & $-\infty$ & 4.95 & $\mathbf{5 . 1 6}$ & 5.13 & 4.75 & 3.63 & 2.32 & 1.02 \\
\hline
\end{tabular}

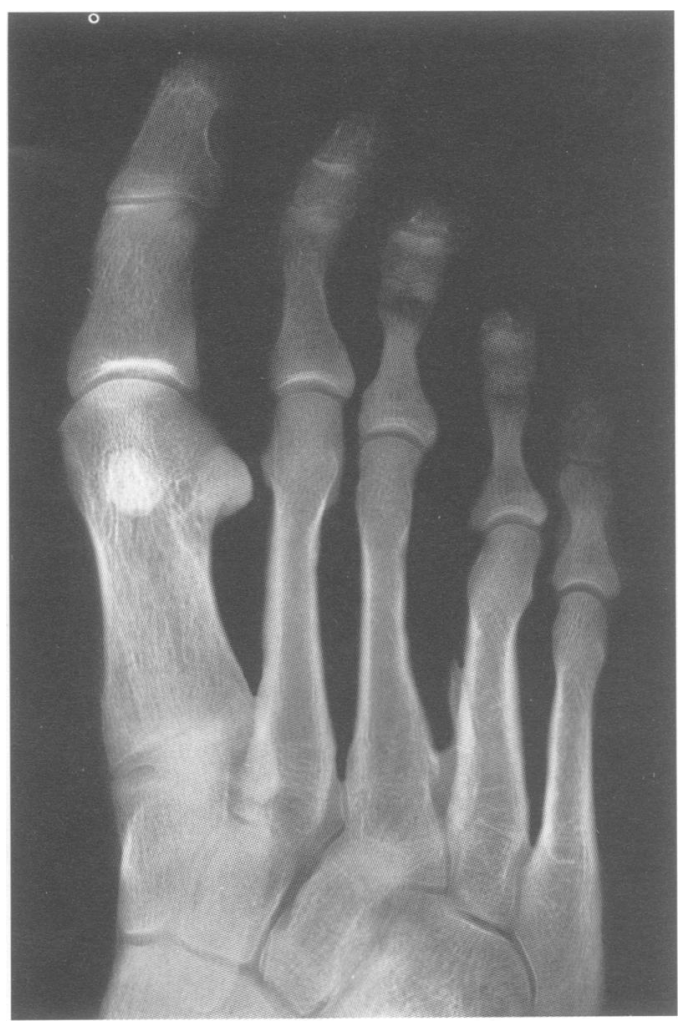

Figure 4 Foot radiograph of III.26 showing an apparent vestigial metatarsal bone lying between the third and fourth metatarsals.

four limb postaxial polydactyly but seven had mixed four limb polydactyly with central polydactyly of one or more limbs. One person had postaxial polydactyly of the hands and cutaneous syndactyly of the second and third toes of both feet. The central polydactyly (also referred to as mesoaxial or insertional polydactyly) typically includes partial osseous syndactyly with proximal fusion of the metacarpals and is characteristic of only a few syndromes. ${ }^{18}$ One subject had evidence of partial development of a sixth metatarsal of the foot. The radiograph of this limb shows a thin calcified structure medial to the third metatarsal that appears to be an underdeveloped metatarsal (fig 4).

Flexible fibreoptic direct laryngoscopy was used to examine the larynx of 10 persons in family 1 . Two of the 10 subjects had a bifid epiglottis and one person had a misshapen, angled epiglottis. One subject with bifid epiglottis also had a small posterior laryngeal cleft. These malformations were not associated with aspiration, recurrent pneumonia, or other voice or swallowing disorders in these patients.
LINKAGE ANALYSIS

Initial linkage was noted to marker D7S672 with a lod score of 1.09 at $\theta=0.25$. Two point linkage analyses with nearby markers showed close linkage to D7S691 with a lod score of 7.0 at $\theta=0$ (table 2) The peak two point lod score was 8.4 at $\theta=0.025$ with D7S678. Multipoint analyses of this region were performed using D7S521, D7S678, D7S691, and D7S621. These analyses gave a peak lod score of 13.5 near D7S691 on 7p13 (fig 5). Haplotype analysis using the Généthon map marker order showed that there were three double recombinants in these two families. We hypothesised that the genetic ordering of markers was incorrect and pursued physical mapping to attempt to resolve these double recombinants. YAC based physical mapping of this region ${ }^{13-17}$ showed a different order for these markers, shifting D7S678 in a centromeric direction. The Généthon order was tel-D7S678D7S521-D7S691-cen, whereas the physical order placed D7S678 centromeric of D7S691. Analysis of the reordered haplotypes in the two families showed that this marker order eliminated double recombinants in the region (fig 1). The YAC based physical map of this region, including ESTs and genes (GLI3 and inhibin $\beta A$, INHBA) is shown in fig 6 Specifically, the deduced physical order is tel-D7S521-INHBA-D7S691-GLI3-D7S678D7S621-D7S1818-cen (the latter two markers were ordered in the experiments but are not shown in fig 6). Thus, on genetic and physical grounds, INHBA and GLI3 could not be excluded as candidate genes for this disorder.

\section{Discussion}

CLINICAL CONSIDERATIONS

The diagnosis of PHS in family 1 was made after the evaluation of IV.8, who presented with ptosis and polydactyly. According to available medical records and the medical history, the diagnosis of PHS was not considered previously in this family although two other people (III.17 and IV.18) had been diagnosed with polydactyly and hypothalamic hamartomas.

The CNS manifestations of the disorder in family 1 are variable, but range in severity from moderate to asymptomatic. The presence of gelastic epilepsy in III. 17 is probably the result of the hamartoma because of the rarity of this form of epilepsy and its frequent association with hypothalamic hamartomas. ${ }^{19}$ The rarity of symptoms referable to the hamartoma in family 1 and the lack of improvement in those with sporadic $^{1920}$ and familial ${ }^{6}$ hamartomas who have undergone extirpation of hamartomas for various symptoms suggest that operative intervention is rarely indicated.

A characteristic of the early case reports of PHS was the association of the hamartoma with endocrine dysfunction. This association ranged from panhypopituitarism ${ }^{1}$ to isolated precocious puberty. ${ }^{5}$ Of the 10 known or reported families with inherited PHS, only one case has been associated with endocrine dysfunction. ${ }^{5}$ The findings in family 1 are consistent with the association of endocrine dysfunction with sporadic, but not familial, 


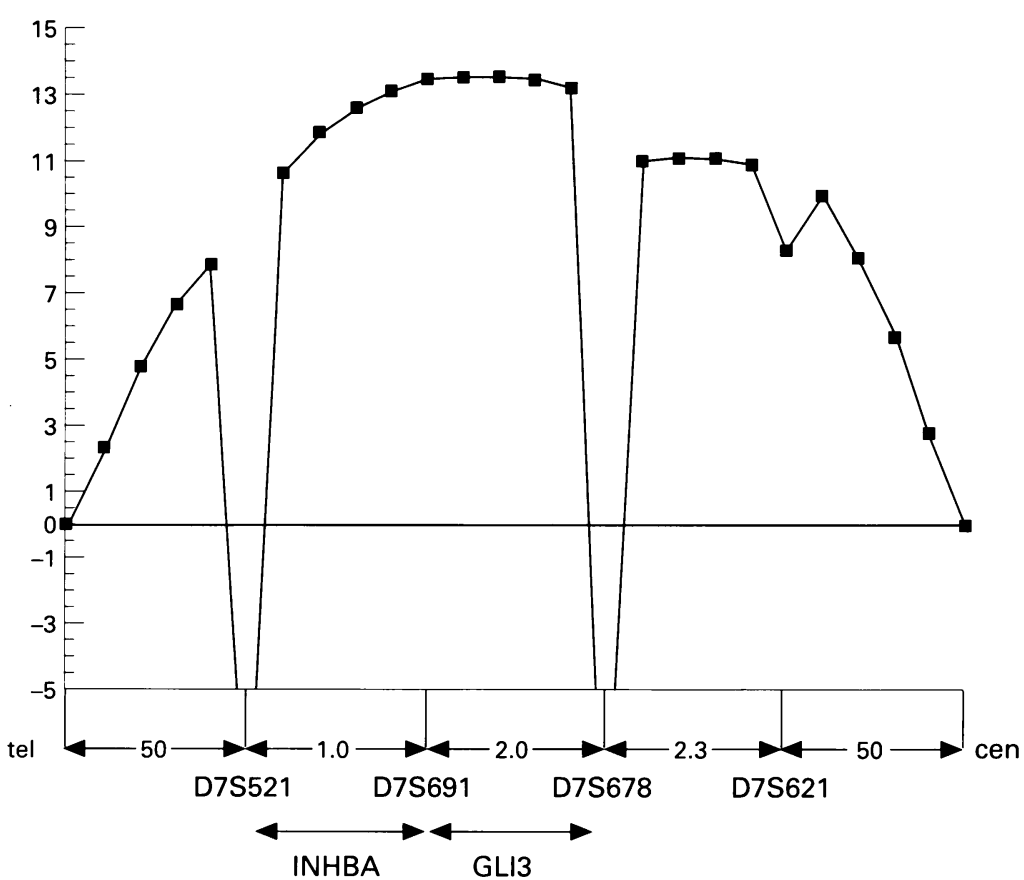

Figure 5 Multipoint linkage results of two separate four point analyses of PHS and three STRP markers. The $X$ axis of the graph is non-linear and shows five linkage scores in each interval. The lengths of the intervals are specified on the $X$ axis. The two candidate genes, INHBA and GLI3, are shown in the intervals that they have been assigned by physical mapping. The notch in the results at $55.3 \mathrm{cM}$ is the result of uninformative genotypes at D7S621.

PHS. None of the 22 affected persons in family 1 has documented endocrine dysfunction and there is no history of precocious puberty.

The finding of epiglottic clefts in family 1 is remarkable because it is an extraordinarily rare malformation. There are 16 case reports of bifid epiglottis tabulated in a recent review. ${ }^{21} \mathrm{~A}$ number of the older case reports of PHS have included descriptions of epiglottic and laryngeal clefts. ${ }^{122}$ This epiglottic malformation, together with the metacarpal or metatarsal polysyndactyly, and the hypothalamic hamartoma can be used to determine the embryological timing of the developmental disturbance in this disorder. The epiglottis, limb paddle, and hypothalamus all form during the seventh week of gestation. ${ }^{23}$ Thus the gene that causes this disorder must act during or before that time to alter these early developmental processes. The issue of whether sporadic and familial PHS are a single entity or are aetiologically heterogeneous has been debated elsewhere. ${ }^{6}$ However, clinical data cannot definitively address this hypothesis, which must await molecular analysis.

\section{LINKAGE ANALYSIS}

The mapping of the PHS phenotype to a delimited region within $7 \mathrm{p} 13$ raised the possibility that PHS and Greig cephalopolysyndactyly syndrome (GCPS) were allelic disorders. GCPS has been shown to be the result of translocations or deletions in the GLI3 gene that cause an abnormal phenotype by the mechanism of haploinsufficiency. ${ }^{24}$ Although PHS and GCPS are clearly distinct phenotypes, the similarity of the disorders is intriguing. ${ }^{25} 26$ Both have polysyndactyly, craniofacial features, and are inherited in an autosomal dominant pattern. Nevertheless there are major differences between the disorders. Central polysyndactyly has not been associated with GCPS. Preaxial duplication of the toes has been described in a single, atypical, sporadic case of PHS. ${ }^{26}$ Hypertelorism and frontal prominence, which are common in GCPS, are not reported in PHS. No cases of GCPS have been reported to have a hypothalamic hamartoma. There is significant variability in the polydactyly in both families analysed in this study. However, other than mild widening of the hallucal phalanges on $x$ ray, this variability does not include partial duplications of the thumbs or big toes. Therefore, given the findings of colocalisation and some phenotypic overlap of the two disorders, we concluded that PHS and GCPS were clinically distinct phenotypes and that GLI3 was a candidate gene for PHS on clinical and genetic grounds.

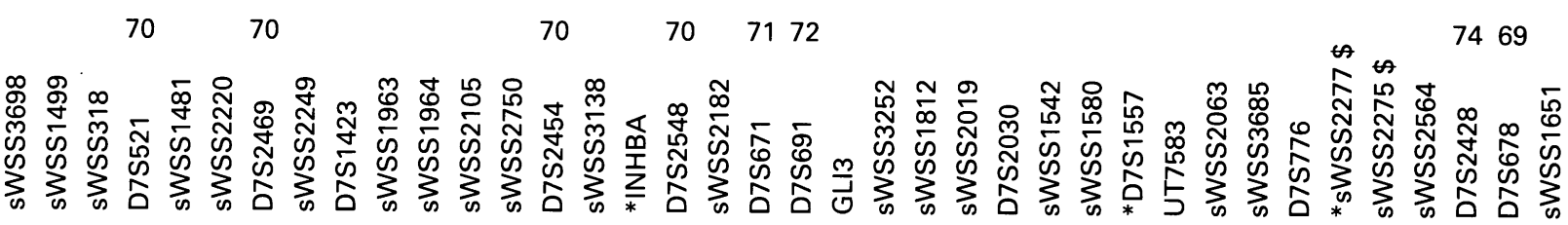

$$
\text { ptel }
$$

Figure 6 YAC based physical map. Shown here is a portion of the YAC contig map for the region of chromosome $7 p 15$ described in the text. This map was constructed as part of a larger effort to derive a complete physical map of chromosome $7 .{ }^{13-17}$ Along the top are listed the STSs. For the Génethon genetic markers, the genetic map position (in cumulative cM from pter) are indicated above the marker name. Uncharacterised ESTs are designated by a \$ sign. Markers that are not uniquely ordered on the physical map have an asterisk between them. Note that D7S521, D7S2469, D7S1423, D7S2454, and D7S2548 are not uniquely ordered on the Généthon map. Marker D7S678, which the Généthon map places telomeric (left) of D7S521, physically maps adjacent to D7S2428. This ordering of markers eliminates apparent double crossovers in III.25 and IV.8 in family 1 and V.1 in family 2 (see fig 1 ). Only a minimal set of YACs are depicted in the figure. A complete view of the contig map is available in the Genomes Division of Genbank (see 
On the basis of these data we have performed and previously reported mutation screening of GLI3 in PHS patients. We have found frameshift mutations in GLI3 in two small families (two and four affected, respectively) but no mutation has been identified in the families analysed in this linkage study. ${ }^{27}$ The determination of mutations in these other two families coupled with the linkage reported in the two large families in this paper strongly suggests that mutations in GLI3 are responsible for autosomal dominant PHS in the larger mildly affected families reported here. That GLI3 mutations also cause PHS in the severe sporadic cases remains to be determined. Taken together, the results showing that GCPS is caused by haploinsufficiency, that small families with moderate PHS have frameshift mutations, and that large mildly affected PHS families are tightly linked to GLI3 suggest that detailed genotype-phenotype correlations will provide important insights into human developmental anomalies and the function of GLI3 in normal development.

The authors thank Kathryn Peters, Michael Gambello, Rosita Kirshman, Howard Levy, and Deborah Stone for assistance in evaluating family 1 . John Powell and Jim Tomlin assisted with the IBM SP2 computer Dr Graham receives support from the the IBM SP2 computer. Dr Graham receives support from the SHAREs child disability center and the Steven Spielberg pediatric research center. Lawrence Brody, Robert Nussbaum, and Anthony Wynshaw-Boris gave helpful comments on the study and this manuscript. This study would not have been

1 Hall JG, Pallister SK, Clarren SK, et al. Congenital hypothalamic hamartoblastoma, hypopituitarism, imperforate anus, and postaxial polydactyly-a new syndrome? Part I. Clinical, causal, and path

2 Clarren SK, Alvord EC, Hall JG. Congenital hypothalamic hamartoblastoma, hypopituitarism, imperforate anus, and postaxial polydactyly-a new syndrome? Part II. Neuropathological considerations. Am f Med Genet 1980;7:7583.

Biesecker LG, Abbott M, Allen J, et al. Report from the workshop on Pallister-Hall syndrome and related disorders. Am $\mathcal{F}$ Med Genet 1996;65:76-81.

4 Biesecker LG, Graham JM Jr. Syndrome of the month. Pallister-Hall syndrome: $\mathcal{F}$ Med Genet 1996;33:585-9.

5 Topf KF, Kletter GB, Kelch RP, Brunberg JA, Biesecker LG. Autosomal dominant transmission of the Pallister-Hall syndrome. F Pediatr 1993;123:943-6.

6 Grebe TA, Clericuzio C. Autosomal dominant inheritance of a hypothalamic hamartoma associated with polysyndactyly: heterogeneity or variable expressivity? $\mathrm{Am}$ polysyndactyly: heterogeneity
7 Biesecker LG, Kang S, Schäffer AA, et al. Exclusion of candidate loci and cholesterol biosynthetic abnormalities in didate loci and cholesterol biosynthetic abnormalities in 51 .

8 Cottingham RW Jr, Idury RM, Schäffer AA. Faster sequential genetic linkage computations. Am f Hum Genet 1993;53:252-63.

9 Schäffer AA, Gupta SK, Shriram K, Cottingham RW Jr Avoiding recomputation in linkage analysis. Hum Hered 1994;44:225-37.

10 Lathrop GM, Lalouel JM, Julier C, Ott J. Strategies for multilocus analysis in humans. Proc Natl Acad Sci USA 1984;81:3443-6.

11 Gupta SK, Schäffer AA, Cox AL, Dwarkadas S, Zwaenepoel W. Integrating parallelization strategies for linkage analysis. Comp Biomed Res 1995;28:1 16-39.

12 Amza C, Cox AL, Dwarkadas S, et al. TreadMarks: shared memory computing on networks of workstations. IEEE Computer 1996;29:18-28.

13 Bouffard GG, Iyer LM, Idol JR, et al. A collection of 1814 human chromosome 7-specific STSs. Genome Res 1997;7: 59-64.

14 Green ED, Green P. Sequence-tagged site (STS) content mapping of human chromosome: theoretical consideramapping of human chromosome: theoretical considera-

15 Green ED, Mohr RM, Idol JR, et al. Systematic generation of sequence-tagged sites for physical mapping of human chromosomes: application to the mapping of human chromosome 7 using yeast artificial chromosomes. Genomics 1991;11:548-64.

16 Green ED, Idol JR, Mohr-Tidwell RM, et al. Integration of physical, genetic, and cytogenetic maps of human chromosome 7: isolation of and analysis of yeast artificial chromosomes for 117 mapped genetic markers. Hum Mol Genet 1994;3:489-501.

17 Green ED, Braden VV, Fulton RS, et al. A human chromosome 7 yeast artificial chromosome (YAC) resource: construction, characterization, and screening. Genomics 1995;25:170-83.

18 Poznanski AK. The hand in radiologic diagnosis. 2nd ed. Philadelphia: Saunders, 1984:266-78.

19 Breningstall GN. Gelastic seizures, precocious puberty, and hypothalamic hamartoma. Neurology 1985;35:1 180-3.

20 Graham JM Jr, Harris M, Frank JE, Little GA, Klein RZ. Congenital hypothalamic hamartoblastoma syndrome: natural history and genetic implications. In: Papadatos CJ, Bartsocas CS, ed. Endocrine genetics and genetics of growth. Bew York: Alan R Liss, 1985:163-74.

21 Goldenberg JD, Holinger LD, Bressler FJ, Hutchinson LR. Goldenberg JD, Holinger LD, Bressler FJ, Hutchinson LR

22 Graham JM Jr, Brown FE, Saunders RL, et al. Bifid epiglottis, hand abnormalities, and congenital hypopituitarism. Lancet 1985;ii:443.

23 Moore KL, Persaud TVN. The developing human: clinically oriented embryology. 5th ed. Philadelphia: W B Saunders, 1993.

24 Vortkamp A, Gessler M, Grzeschik KH. GLI3 zinc finge gene interrupted by translocations in Greig syndrome gene interrupted by translocation

25 Penman Splitt M, Wright C, Perry R, Burn J. Autosoma dominant transmission of the Pallister-Hall syndrome. Clin dominant transmission of

26 Finnigan DP, Clarren SK, Haas JE. Extending the PallisterHall syndrome to include other central nervous system malformations. Am $\mathcal{F}$ Med Genet 1991;40:395-400.

27 Kang S, Graham JM Jr, Olney AH, Biesecker LG. GLI3 frameshift mutations cause autosomal dominant PallisterHall syndrome. Nat Genet 1997;15:266-8. 